\title{
RELATOS DE PESQUISAS
CONVERGÊNCIAS E ENTRELACES ENTRE MEDIAÇÃO E
GESTÃO DA INFORMAÇÃO:
INDÍCIOS E PERSPECTIVAS APRESENTADOS NA
LITERATURA DA CIÊNCIA DA INFORMAÇÃO
}

Raquel do Rosário Santos

Doutora em Ciência da Informação pela Universidade Federal da Paraíba, Brasil. Professora da Universidade Federal da Bahia, Brasil.

E-mail: quelrosario@gmail.com

Luciana de Albuquerque Moreira

Doutora em Informação e Comunicação em Plataformas Digitais pela

Universidade do Porto, Portugal. Professora da Universidade Federal do

Rio Grande do Norte, Brasil.

E-mail: lucianamoreiraufrn@gmail.com

Monica Marques Carvalho Gallotti

Doutora em Informação e Comunicação em Plataformas Digitais pela

Universidade do Porto, Portugal. Professora da Universidade Federal do

Rio Grande do Norte, Brasil.

E-mail: monica mcg@gmail.com

\begin{abstract}
Resumo
As atividades de gestão da informação são entendidas, nessa comunicação, como ações implícitas de mediação da informação, visto que é inerente a essas atividades o propósito de auxiliar o usuário em seu desenvolvimento e apoiá-lo na apropriação da informação. O gestor da informação deve atuar de maneira a atender às demandas e suprir as necessidades informacionais, além de apoiar os sujeitos no desenvolvimento de suas práticas. Para tanto, é preciso que o gestor atue na perspectiva de mediar a informação, desenvolvendo ações conscientes. Assim, o objetivo deste trabalho foi o de encontrar convergências entre as áreas de gestão da informação (GI) e mediação da informação (MI), a partir da análise dos artigos científicos que tratam sobre esses temas na Base de Dados Referenciais de Artigos de Periódicos em Ciência da Informação (BRAPCI). A metodologia utilizada foi a da pesquisa bibliográfica, e os dados foram analisados por meio da abordagem qualitativa e da técnica de análise de conteúdo. A pesquisa evidenciou que a maioria dos pesquisadores trata a mediação e a gestão como elementos que mantêm algum nível de aproximação, mas, em seus estudos, focalizam uma ou outra temática, sem fazer uma interligação entre elas. As comunicações focalizaram a gestão da informação ou mediação da informação. Em alguns casos, esses temas foram apresentados de maneira subliminar. Assim, defendese a relevância do desenvolvimento de estudos que conduzam a gestão com base nos fundamentos propostos pela mediação da informação, o que poderá ampliar a perspectiva que o gestor terá do seu fazer. Nesse sentido, um mediador da informação é que apoiará a adoção de uma cultura organizacional em que os demais profissionais atuem também como mediadores, na perspectiva de possibilitar uma relação dialógica com os usuários que apoiarão o uso e a apropriação da informação.
\end{abstract}

Palavras-chave: Mediação da informação. Gestão da informação. Produção científica - Ciência da Informação. 


\title{
CONVERGENCES AND INTERLACES BETWEEN MEDIATION AND INFORMATION MANAGEMENT: EVIDENCE AND PERSPECTIVES PRESENTED IN INFORMATION SCIENCE SCHOLARLY LITERATURE
}

\begin{abstract}
In this work, information management activities are understood as implicit information mediation actions. This is due to the fact that these activities aim to help users in their own development by means of information appropriation. The information manager should must act in order to meet user demands, attend information needs, as well as support them the development of their information practices. Therefore, they must act from the perspective of information mediation, developing conscious actions. This work aimed to seek convergence between the areas of information management (IM) and information mediation (IM), based on the analysis of scholarly articles dealing with these issues present in the Base de Dados Referenciais de Artigos de Periódicos em Ciência da Informação (BRAPCI). The methodology used was of bibliographic research, with a qualitative approach to data analysis and content analysis technique. The research points out that most researchers treat information mediation and management as elements that maintain some level of approximation, but the majority of these studies focus on these issues separately, without an indication of possible connections. In other cases, these subjects are subliminally presented. Thus, the research points out the need for the development of studies that consider theoretical and practical prepositions in accordance to information mediation. It is an alternative to broaden the information management spectrum and support organizational culture where other professionals are also act as mediators, favoring a dialogical relationship with users that will support the information use and appropriation.
\end{abstract}

Keywords: Information mediation. Information management. Scientific production - Information Science.

\section{INTRODUÇÃO}

Em tempos de excesso de informação, cuja produção e disseminação são potencializadas pelas tecnologias de informação e comunicação (TIC), muitas vezes, sem contar com a confiabilidade que garanta uma utilização segura para tomar decisões e comprovar as ações humanas, são essenciais a gestão dos fluxos informacionais e a atuação consciente e mediadora dos profissionais da informação. O gestor da informação deve atuar de maneira a suprir as necessidades informacionais e apoiar os sujeitos no desenvolvimento de suas práticas. Para isso, o gestor deve atuar na perspectiva de mediar a informação, desenvolvendo ações conscientes, sistematizadas e que apoiem os sujeitos no processo de apropriação da informação.

Nesse contexto, justifica-se a realização de pesquisas que investiguem a inter-relação entre a gestão e a mediação da informação, o que poderá contribuir com a reflexão tanto dos agentes quanto dos pesquisadores na atuação interligada desses temas tratados no campo da Ciência da Informação. Vale ressaltar que o interesse pela delimitação desses temas também se deu a partir da percepção das interligações lógicas entre eles, assimiladas em leituras diversas, em que os fluxos de informação organizados e a necessidade de comunicação desses fluxos com pessoas e/ou em organizações estão sempre em evidência. Por outro lado, as comunicações científicas da Ciência da Informação deixam implícitas a abrangência e a necessidade de relações. No entanto, foi necessário um olhar mais atento para, de fato, buscar respostas para os indícios. A realização do estudo justificou-se porque propôs ampliar a base de conhecimento sobre o assunto. Assim, o objetivo deste artigo foi de analisar as convergências entre a gestão da informação (GI) e a mediação da informação (MI), a partir do levantamento dos artigos científicos que tratam sobre esses temas na Base de Dados Referenciais de Artigos de Periódicos em Ciência da Informação (BRAPCI).

Quanto aos procedimentos metodológicos, trata-se de uma pesquisa descritiva, para cujo desenvolvimento foi empregado o estudo bibliográfico e cuja amostra foram as

Perspectivas em Gestão \& Conhecimento, João Pessoa, v. 10, número especial, p. 54-71, mar. 2020. 
produções científicas disponibilizadas na BRAPCI. Para o processo de coleta dos dados, utilizaram-se os seguintes descritores: 'gestão da informação' and 'mediação'. No total, foram recuperados 21 artigos. No que tange à análise dos dados, foi adotada a abordagem quantitativa, para mensurar os dados, e a qualitativa, à luz da análise de conteúdo proposta por Bardin (1977).

Os temas mediação e gestão da informação são apresentados nesta comunicação a partir de uma reflexão sobre as convergências e os entrelaces percebidos na literatura da área de Ciência da Informação. Para tanto, discute-se, inicialmente, sobre as bases conceituais a respeito de cada um dos temas, com vistas a contextualizar o assunto. Em seguida, a partir do levantamento bibliográfico realizado na Brapci, expõem-se os resultados da pesquisa e os analisam à luz de categorias eleitas como balisadoras para nortear as reflexões. Por fim, são apresentadas as considerações que foram alcançadas neste estudo.

\section{AS LIGAÇÕES ENTRE A MEDIAÇÃO E A GESTÃO DA INFORMAÇÃO}

O termo mediação vem sendo estudado e adotado por pesquisadores e profissionais de diversas áreas do conhecimento, como, por exemplo, a de Teologia, a de Educação e da Saúde e, mais recentemente, a área dal. Ao estudar as bases epistemológicas da mediação no campo da Ciência da Informação, Silva e Gomes (2013) afirmaram que esse tema vem sendo tratado, especialmente, nos Séculos XIX, XX e XXI, no desenvolvimento de suas práticas e na reflexão sobre elas. Assim, a mediação da informação adquire fundamentação quando refletida por meio de suas ações voltadas para o desenvolvimento dos agentes mediadores e mediados, que atuam com e nos dispositivos ${ }^{1}$ informacionais, gerando e apoiando encontros e acesso à informação que subsidiam o uso e a apropriação desse elemento.

Ao tratar sobre o desenvolvimento cognitivo dos sujeitos a partir das interações sociais, Vygotsky (2000) afirma que, entre o objeto e o sujeito, e deste até o objeto, existe outra pessoa. Com base nas concepções apresentadas pelo autor, pode-se afirmar que a relação entre o sujeito e a nova informação só ocorrerá por meio de um processo de mediação. Assim, ao planejar, preservar, organizar e disseminar a informação, o mediador está possibilitando que o processo de desenvolvimento dos sujeitos ocorra, visto que, nesse processo, existirá a aproximação entre o sujeito e o objeto, que auxiliará em seu crescimento cognitivo, social e cultural.

A partir dessa reflexão, pode-se constatar que a mediação da informação está relacionada à interferência de um mediador no processo entre a identificação e o auxílio de um problema informacional apresentado por um usuário. Essa afirmação toma como referência a conceituação apresentada por Almeida Júnior $(2015$, p. 25), para quem a mediação da informação é

[...] toda ação de interferência - realizada em um processo, por um profissional da informação e na ambiência de equipamentos informacionais -, direta ou indireta; consciente ou inconsciente; singular ou plural; individual ou coletiva; visando a apropriação de informação que satisfaça, parcialmente e de maneira momentânea, uma necessidade informacional, gerando conflitos e novas necessidades informacionais.

\footnotetext{
${ }^{1}$ Dispositivo é entendido a partir do conceito apresentado por Pieruccini (2007, p. 35), como um “[...] signo, um mecanismo de intervenção sobre o real, que atua por meio de formas de organização estruturada, utilizando-se de recursos materiais, tecnológicos, simbólicos e relacionais, que atingem os comportamentos e as condutas afetivas, cognitivas e comunicativas dos indivíduos."
}

Perspectivas em Gestão \& Conhecimento, João Pessoa, v. 10, número especial, p. 54-71, mar. 2020. 
Conforme a reflexão apresentada pelo autor, pode-se inferir que, quando as ações de mediação da informação são realizadas consciente e efetivamente, não só apoiam o atendimento de uma necessidade informacional, como também auxiliam o sujeito a gerar novos conhecimentos e propiciam conflitos e novas necessidades informacionais.

Ainda referente às ações da mediação da informação, destaca-se a divisão proposta por Almeida Júnior (2015), que assevera que existem a "mediação implícita da informação" e a "mediação explícita da informação". A primeira refere-se às atividades que são desenvolvidas sem a presença física e imediata dos usuários. Já a segunda, com a presença real do usuário, é inevitável para o desenvolvimento das atividades. Assim, podem-se compreender as atividades de gestão da informação como ações implícitas de mediação da informação, visto que é inerente a essas atividades o propósito de auxiliar o usuário em seu desenvolvimento, entretanto a interação entre os agentes mediadores e os usuários se dá de maneira indireta.

Como a mediação tem um fim transformador, a gestão da informação, a partir de processos concretos de organização e de tratamento de fluxos de informação, objetiva compartilhar e transformar ambientes de informação. "Portanto a gestão da informação é um processo que abarca outros processos e não pode fugir de sua condição de mediadora para se chegar ao uso da informação" (PINHEIRO, 2008, p. 46).

Ao refletir sobre a afirmação de Pinheiro (2008) e aproximá-la do conceito de Almeida Júnior (2015), percebe-se que a mediação da informação ocorre por meio de um processo. A partir dessa compreensão, mediar não é um ato imediato, mas uma ação relacionada ao conjunto de práticas e sistemas que auxiliam o profissional da informação a agir para atender às necessidades informacionais dos usuários. Essa percepção também é abordada por Perrotti e Pierruccini (2014), que compreendem que tal processo pressupõe a transmissão de conteúdos informacionais vinculada à construção de sentidos.

Nesse contexto, pode-se estabelecer uma relação com a gestão da informação, que, como já mencionado, ocorre por meio de um processo que envolve outros processos, a partir das "subjetividades dos insights, das percepções, do individual e a objetividade do que já foi vivenciado e agora se apresenta ordenado e coletivo" (PINHEIRO, 2008, p. 44). Corroborando essa linha de pensamento, Duarte (2011, p. 162) afirma que "[...] a Gl é o estudo dos processos informacionais, do modo como a informação pode ser organizada, armazenada, recuperada e utilizada para a tomada de decisões e para a construção do conhecimento."

Gomes (2014, p. 55) refere que "[...] a mediação representa uma ação também dependente do nível de conscientização do agente que a realiza em relação a esse objetivo, como também quanto ao seu papel protagonista, que, nessa condição, interfere no meio [...]". Esse nível de conscientização do agente pode ser relacionado ao contexto em que os agentes mediadores se colocam, com determinado acervo ou recurso informacional que está armazenado e, portanto, passível de ser mediado. Assim, a mediação pode ser entendida como um processo.

Essa compreensão implica também a realização consciente das atividades de gestão, que é uma atividade de mediação e, nesse sentido, considera as dimensões da mediação da informação defendidas por Gomes $(2014,2016,2017)$. De acordo com a autora, a mediação da informação tem cinco dimensões: a dialógica, a estética, a formativa, a ética e a política. A efetividade da mediação da informação é consequência do alcance dessas cinco dimensões.

É preciso evidenciar o cenário de atuação do processo de mediação, que também é fundamento para as práticas de gestão da informação. Nesse sentido, a dialogia propicia os espaços de interação, que permite a crítica e a criatividade, o que confere prazer aos sujeitos que vivenciam o fato de realizarem as ações e que, nessa situação, alcançam a dimensão estética, oportunizando o processo de aprendizagem e de formação, quando a mediação atinge sua dimensão formativa (GOMES, 2014, 2016).

Perspectivas em Gestão \& Conhecimento, João Pessoa, v. 10, número especial, p. 54-71, mar. 2020. 
Conforme Gomes (2016) a apropriação da informação e, consequentemente, a geração de novos saberes e conhecimentos por parte dos sujeitos mediados só serão possíveis por meio da interferência consciente e competente do mediador, para evitar a manipulação, portanto, a partir do alcance da dimensão ética. Por fim, ao desenvolver reflexões acerca das próprias ações mediadoras, o mediador se conscientiza de sua condição de protagonista social e efetiva a dimensão política da mediação da informação (GOMES, 2016, 2017).

Pode-se afirmar que, como uma ação de mediação implícita da informação, a gestão da informação deve ser desenvolvida com o objetivo de apoiar o sujeito mediado em seu desenvolvimento e na conquista da autonomia informacional e do protagonismo social. Nessa perspectiva, Valentim (2004) define a gestão da informação como

Um conjunto de estratégias que visa identificar as necessidades informacionais, mapear os fluxos formais de informação nos diferentes ambientes da organização, assim como sua coleta, filtragem, análise, organização, armazenagem e disseminação, objetivando apoiar o desenvolvimento das atividades cotidianas e a tomada de decisão no ambiente corporativo.

Corroborando o conceito apresentado pela autora, Pinto $(2017$, p. 149) afirma que

Se trata de uma GI que, iniciando-se com a 'gestão de documentos' (em papel), abarca progressivamente a 'gestão da tecnologia' (automatização), a 'gestão de recursos de informação', a análise, seleção e organização de informação estratégica, bem como a fase da respetiva gestão, evidenciando os vários modelos, diferentes formas de compreender e aplicar o 'ciclo da informação' em contexto organizacional.

A partir dessa afirmação, pode-se constatar que a efetividade da gestão da informação ocorre por meio de um processo, em que existe um conjunto de ações implícitas e a adoção de dispositivos mediadores. Dessa maneira, a gestão da informação pode ser compreendida como o "[...] estudo, a concepção, a implementação e o desenvolvimento dos processos e dos serviços inerentes ao fluxo infocomunicacional, permitindo a construção de modelos de operacionalização de máxima eficiência e rentabilização" (PINTO, 2017, p.152).

Para exemplificar como se dão esses processos, apresenta-se um dos modelos de relevância na literatura da área de gestão da informação, que é o modelo processual de adminstração da informação de Choo.

Figura 1 - Modelo processual de adminstração da informação

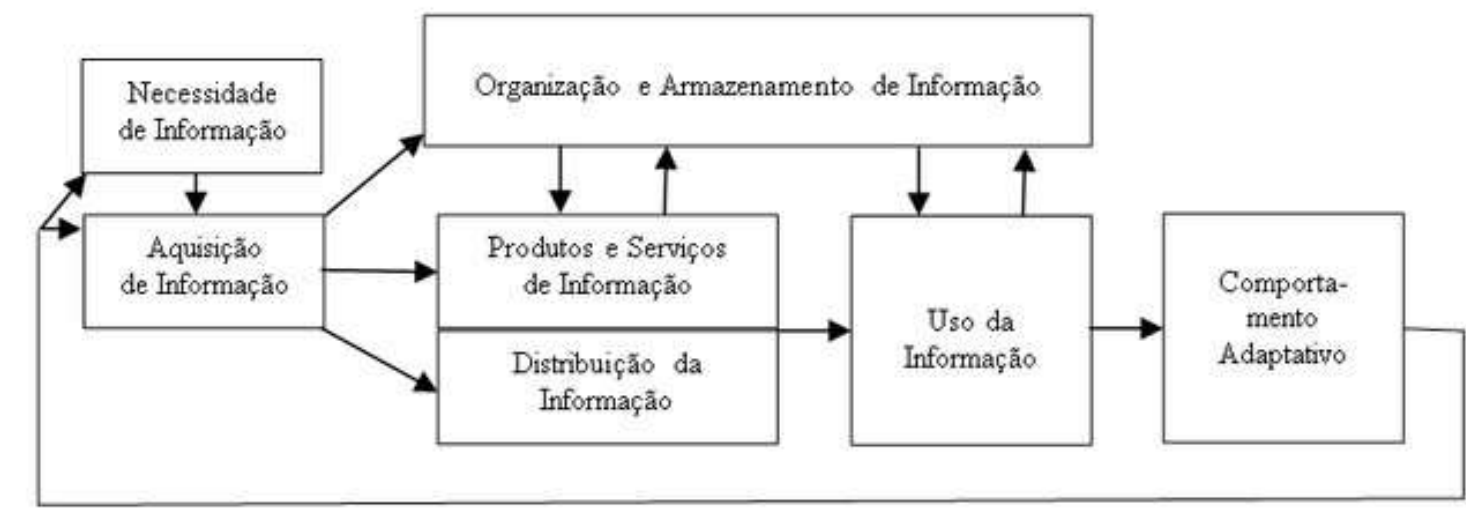

Fonte: Choo (2006)

Perspectivas em Gestão \& Conhecimento, João Pessoa, v. 10, número especial, p. 54-71, mar. 2020. 
De acordo com Choo, o modelo é formado por seis processos correlatos impulsionados a partir da identificação das necessidades de informação. As necessidades podem ser espontâneas ou induzidas e são definidas como um "[...] vetor (constituído por um ou vários impulsos de ordem diversa) que predispõe ou orienta diretamente um indivíduo a buscar e a (re)produzir informação em determinada situação dentro de um determinado contexto tendo como pano de fundo um meio ambiente" (SILVA, 2006, p.156). Essa definição corrobora a colocação de que as necessidades de informação "[...] nascem de problemas, incertezas e ambiguidades encontradas em situações e experiências específicas" (CHOO, 2006, p.405). A partir da identificação das necessidades informacionais, segue-se com a aquisição de informação (em um sistema de informação qualquer, ou em diferentes fontes de informação). Nessa etapa, surgem duas demandas opostas: a multiplicidade das necessidades de informação e a limitação cognitiva do homem em selecionar as fontes ideais para suprir as necessidades explicitadas e demandadas (CHOO, 2006).

A organização e o armazenamento da informação compõem a terceira etapa do modelo. De acordo com Silva (2006, p.157), a organização [e o armazenamento] são "[...] a extenção da informação como meio de possibilitar a comunicação e o uso." E complementa que esse processo envolve a metainformação, representada pelos

[...] elementos que identificam e permitem o acesso a uma unidade informacional específica. Trata-se, em suma, da extensão da informação como meio de possibilitar a comunicação e o uso. Resumir, catalogar, inventariar, classificar, indexar, elaborar bibliografias e índices [...] e correspondem a técnicas de representação da informação (dos conteúdos), seja ela de que tipo for. (SILVA, 2006, p.157).

A etapa seguinte, chamada de produtos e serviços de informação, trata justamente das fontes de informação que compõem os acervos das unidades de informação. Os produtos e os serviços de informação podem ser representados pelos repositórios digitais, portais de informação, guias, manuais, serviços de informação e referência etc. que irão satisfazer às necessidades de informação expressas no início do modelo de gestão da informação.

Em seguida, dá-se a distribuição da informação, equivalente à disseminação da informação, etapa em que é possível associar a importância das ações de mediação da informação como facilitadora dessa distribuição, tornando-se um canal direto de comunicação com usuários de informação, seja a partir da interação com o usuário, ou no próprio acesso a um catálogo. De acordo com Choo (2006, p. 414), "O objetivo da distribuição da informação é de promover e facilitar a partilha de informações, que é fundamental para a criação de significado, a construção de conhecimento e a tomada de decisões."

Diretamente relacionado à distribuição, está o uso da informação, que depende unicamente do interesse do usuário pela informação distribuída, já sinalizada anteriormente com a necessidade informacional. De acordo com Teruel, o uso

Puede ser resultado, por ejemplo, de la consulta a una fuente de información e incluso de una conversación informal com outra persona, donde determinada información es recibida de forma casual y puede llhegar a satisfacer una necesidad o un deseo que previamente no había dado lugar a una demanda (TERUEL, 2005, p.75).

Para Choo (2006, p. 415), "O uso da informação é um processo social dinâmico de pesquisa e construção que resulta na criação de significado, na construção de conhecimento e

Perspectivas em Gestão \& Conhecimento, João Pessoa, v. 10, número especial, p. 54-71, mar. 2020. 
na seleção de padrões de ação." Nesse processo, o autor coloca que cada componente decorre também das interpretações individuais, seja de ordem cognitiva ou emocional.

Depois das seis etapas descritas no modelo processual de administração da informação (identificação das necessidades de informação, aquisição da informação, organização e armazenamento da informação, desenvolvimento de produtos e serviços de informação, distribuição da informação e uso da informação), o modelo traz, ainda, um processo final chamado de comportamento adaptativo, que representa o "Resultado eficiente do uso da informação [...] a seleção e a execução de ações dirigidas para objetivos, mas que também reagem às condições do ambiente." (CHOO, 2006, p. 404), fazendo com que o ciclo recomece a partir da retroalimentação com novas necessidades de informação.

Depois de feita essa explanação sobre o modelo processual de administração da informação, é possível perceber a potencialidade da interação existente entre diversas áreas do conhecimento, impulsionadas pela ações ligadas à gestão da infomação. Na visão de Pinheiro (2008), a gestão da informação e todos os processos de gestão de documentos e gestão do conhecimento estão relacionados e interdependentes. No entanto, a Gl é colocada como um elo entre todos eles. A gestão da informação é posta, assim, como a "[...] mais endógena e estabelece uma orientação informacional quando considera o contexto, os atores e seus objetivos." (PINHEIRO, 2008, p. 48).

Feita essa breve discussão conceitual, compreende-se a interligação entre a mediação e a gestão da informação, porque, "Ao organizar a informação para a sua disponibilização, a GI deve ser um processo mediador que considere e ao mesmo tempo seja instrumento da cultura do coletivo, represente a identidade de um grupo social pela análise crítica de informações, com o objetivo de compartilhar e comunicar." (PINHEIRO, 2008, p.49). Nessa perspectiva, pode-se afirmar que a gestão da informação integra o conjunto de ações implícitas de mediação da informação, entretanto é essa ação que confere sistematização e um conjunto de estratégias para efetivar as demais ações implícitas e explícitas realizadas pelo mediador da informação, como também norteia a elaboração, a adoção e a relação com os dispositivos informacionais.

É preciso que o gestor atue de maneira consciente, a partir da concepção mediadora da informação, apoiando os sujeitos no acesso e no uso dos dispositivos informacionais que poderão favorecer a apropriação da informação e a geração de novos conhecimentos e saberes, além do posicionamento desse sujeito como protagonista social. Assim, além das práticas profissionais, considera-se relevante o desenvolvimento de estudos que identifiquem e observem se e como as produções científicas do campo da Ciência da Informação refletem a inter-relação da gestão e mediação da informação.

\section{METODOLOGIA}

A pesquisa se caracteriza como descritiva. O método adotado foi o estudo bibliográfico, e a amostra envolveu produções científicas disponibilizadas na base de dados BRAPCI referentes ao tema que envolve a mediação da informação e a gestão da informação. Partiu das seguintes questões norteadoras: Quais os indícios de ligação entre a mediação e a gestão da informação evidenciados na produção científica da Ciência da Informação? Essa produção científica apresenta possíveis práticas que ratifiquem essa relação temática? Para responder a esses questionamentos, partiu-se do seguinte objetivo geral: analisar, na produção científica da Ciência da Informação, as ligações entre a mediação da informação e a gestão da informação e os possíveis indícios pragmáticos que demonstram a aproximação entre esses temas.

Para alcançar o objetivo proposto, foi realizado o levantamento bibliográfico das comunicações científicas, disponibilizadas na BRAPCl, que tratam dos temas adotados nesta

Perspectivas em Gestão \& Conhecimento, João Pessoa, v. 10, número especial, p. 54-71, mar. 2020. 
pesquisa - mediação da informação e gestão da informação - como também das possíveis interligações entre eles. As informações foram coletadas no mês de setembro de 2019, por meio da expressão de busca "mediação da informação" e "gestão da informação", utilizando o operador booleano "and" (e). Como resultado dessa busca, foram identificados 21 artigos, apresentados no Quadro 1:

Quadro 1- Artigos científicos indexados na BRAPCl que tratam de mediação da informação e da gestão da informação

\begin{tabular}{|c|c|c|}
\hline Autores & Título & Ano \\
\hline $\begin{array}{c}\text { TARAPANOFF, Kira; SUAIDEN, } \\
\text { Emir José; OLIVEIRA, Cecília } \\
\text { Leite }\end{array}$ & $\begin{array}{l}\text { Funções sociais e oportunidades para } \\
\text { profissionais da informação }\end{array}$ & 2002 \\
\hline FREIRE, Isa Maria & $\begin{array}{c}\text { Acesso à informação e identidade cultural: } \\
\text { entre o global e o local }\end{array}$ & 2006 \\
\hline $\begin{array}{l}\text { FARIAS, Gabriella Belmont de; } \\
\text { VITAL, Luciane Paula }\end{array}$ & $\begin{array}{c}\text { Informação para negócios e políticas de } \\
\text { informação }\end{array}$ & 2007 \\
\hline $\begin{array}{l}\text { ARAÚJO JÚNIOR, Rogério } \\
\text { Henrique; ARAÚJO, Ideliza } \\
\text { Amélia de }\end{array}$ & $\begin{array}{l}\text { Modelo de gestão da informação do } \\
\text { programa de comutação bibliográfica - } \\
\text { COMUT }\end{array}$ & 2008 \\
\hline $\begin{array}{c}\text { FREIRE, Isa Maria; } \\
\text { NATHANHSON, Bruno Macedo }\end{array}$ & $\begin{array}{l}\text { Janelas da cultura local: abrindo } \\
\text { oportunidades para inclusão digital }\end{array}$ & 2009 \\
\hline $\begin{array}{l}\text { CASTRO FILHO, Cláudio } \\
\text { Marcondes de }\end{array}$ & $\begin{array}{c}\text { A pesquisa de graduação: o caso dos TCCs } \\
\text { da USP-Ribeirão em relação aos GTs do } \\
\text { ENANCIB }\end{array}$ & 2010 \\
\hline ALENTEJO, Eduardo da Silva & $\begin{array}{c}\text { Qualidade da informação em Saúde } \\
\text { mediada em biblioteca pela percepção de } \\
\text { seus usuários }\end{array}$ & 2010 \\
\hline $\begin{array}{c}\text { LOPES, Elaine Cristina; } \\
\text { VALENTIM, Marta Lígia Pomim; } \\
\text { ALMEIDA JUNIOR, Oswaldo } \\
\text { Francisco }\end{array}$ & $\begin{array}{l}\text { Disseminação da informação em empresas } \\
\text { de capital aberto e os processos de } \\
\text { mediação da informação }\end{array}$ & 2011 \\
\hline DUARTE, Emeide Nóbrega & $\begin{array}{c}\text { Conteúdos temáticos como subsídios para } \\
\text { indicação de colaboração na Ciência da } \\
\text { Informação: PPGCI/UNESP e PPGCI/UFPB } \\
\text { em evidência }\end{array}$ & 2012 \\
\hline DUARTE, Emeide Nóbrega & $\begin{array}{l}\text { Conexões Temáticas em Gestão da } \\
\text { Informação e do Conhecimento no Campo } \\
\text { da Ciência da Informação }\end{array}$ & 2011 \\
\hline CORDA, Maria Cecília & $\begin{array}{l}\text { Gestão e mediação da informação em um } \\
\text { serviço de referência digital no campo das } \\
\text { Ciências Sociais }\end{array}$ & 2012 \\
\hline $\begin{array}{l}\text { RAMOS, Lúcia Verônica Costa; } \\
\text { FUJINO, Asa }\end{array}$ & $\begin{array}{l}\text { Redes de informação científica e os desafios } \\
\text { para popularização da ciência: estudo de } \\
\text { caso na Rede SIEO - Sistema de Informação } \\
\text { Especializado na Área de Odontologia }\end{array}$ & 2013 \\
\hline JOTTA, Carlos Augusto Ribeiro & $\begin{array}{c}\text { Mediação científica em museus de ciência e } \\
\text { tecnologia: abordagem acerca da coleção de } \\
\text { instrumentos científicos de Claude Henri } \\
\text { Gorceix }\end{array}$ & 2015 \\
\hline $\begin{array}{c}\text { MIRANDA, Ana Cláudia } \\
\text { Carvalho de; GALLOTTI, Mônica } \\
\text { Marques Carvalho; MIRANDA, } \\
\text { Erlano Silva de }\end{array}$ & $\begin{array}{l}\text { A gestão da qualidade como estratégia de } \\
\text { suporte para o desenvolvimento de } \\
\text { coleções em bibliotecas jurídicas }\end{array}$ & 2016 \\
\hline
\end{tabular}

Perspectivas em Gestão \& Conhecimento, João Pessoa, v. 10, número especial, p. 54-71, mar. 2020. 


\begin{tabular}{|c|c|c|}
\hline Autores & Título & Ano \\
\hline $\begin{array}{c}\text { TARAPANOFF, Kira; SUAIDEN, } \\
\text { Emir José; OLIVEIRA, Cecília } \\
\text { Leite }\end{array}$ & $\begin{array}{l}\text { Funções sociais e oportunidades para } \\
\text { profissionais da informação }\end{array}$ & 2002 \\
\hline $\begin{array}{c}\text { SILVA, Jonathas Luiz Carvalho; } \\
\text { FARIAS, Maria Giovanna } \\
\text { Guedes }\end{array}$ & $\begin{array}{l}\text { Abordagens conceituais e aplicativas da } \\
\text { mediação nos serviços de informação }\end{array}$ & 2017 \\
\hline $\begin{array}{c}\text { VARELA, Aída Varela; BARBOSA, } \\
\text { Marilene Lobo Abreu; FARIAS, } \\
\text { Maria Giovanna Guedes }\end{array}$ & $\begin{array}{l}\text { Humanismo e tecnologia na perspectiva da } \\
\text { competência informacional e midiática }\end{array}$ & 2017 \\
\hline $\begin{array}{l}\text { SANTOS, Raquel do Rosário; } \\
\text { FREITAS, Lívia Santos de; } \\
\text { FERREIRA, Héngret Santos; } \\
\text { MIYAMURA, Camila Maria de } \\
\text { Macedo Martins }\end{array}$ & $\begin{array}{l}\text { Expectativas dos usuários quanto ao } \\
\text { desenvolvimento do dispositivo de } \\
\text { comunicação da Biblioteca Universitária }\end{array}$ & 2018 \\
\hline $\begin{array}{c}\text { BALBINO, Giseli Milani } \\
\text { Santiago; CHAGAS, Cíntia } \\
\text { Aparecida } \\
\end{array}$ & $\begin{array}{c}\text { Papel pedagógico do arquivista e sua } \\
\text { inserção na difusão e mediação da } \\
\text { informação }\end{array}$ & 2018 \\
\hline $\begin{array}{l}\text { ALVES, Mariana de Souza; } \\
\text { CORREIA, Anna Elizabeth } \\
\text { Galvão Coutinho; SALCEDO, } \\
\text { Diego Andres }\end{array}$ & $\begin{array}{c}\text { Práticas leitoras e informacionais nas } \\
\text { bibliotecas comunitárias em rede da } \\
\text { Releitura - PE }\end{array}$ & 2018 \\
\hline $\begin{array}{c}\text { SILVA, Rafaela Carolina; } \\
\text { CALDAS, Rosângela Formentini }\end{array}$ & $\begin{array}{l}\text { O método Cross Culture na pesquisa em } \\
\text { Ciência da Informação } \\
\end{array}$ & 2019 \\
\hline
\end{tabular}

Fonte: Dados da pesquisa - 2019

Os discursos presentes no texto foram analisados à luz da análise de conteúdo proposta por Bardin (1977). Para a autora, a técnica possibilita análises temáticas e abrangentes a partir dos conteúdos das mensagens. A partir de então, elegem-se categorias e procede-se à análise propriamente dita. Em decorrência das análises, foram categorizados os temas que, direta ou indiretamente, contemplaram o foco da pesquisa e suas reflexões finais.

$\mathrm{Na}$ próxima seção, apresentam-se os resultados alcançados com base nos objetivos propostos e fundamentados com o aporte teórico e empírico apresentado nesta comunicação.

\section{APRESENTAÇÃO E ANÁLISE DOS RESULTADOS}

Conforme já exposto, o levantamento bibliográfico realizado na BRAPCI resultou em 21 artigos científicos. Foram arrolados artigos no período de 2002 a 2019. No entanto, nesta amostragem, dois artigos foram desconsiderados, pelo fato de não se enquadrarem no escopo da nossa pesquisa, restando assim, 19 artigos a serem analisados. Conforme exposto no Gráfico 1, a maior concentração de trabalhos foi registrada nos anos de 2010 e 2018. 
Gráfico 1-Ocorrência dos assuntos da Gestão da Informação e/ou Mediação da Informação

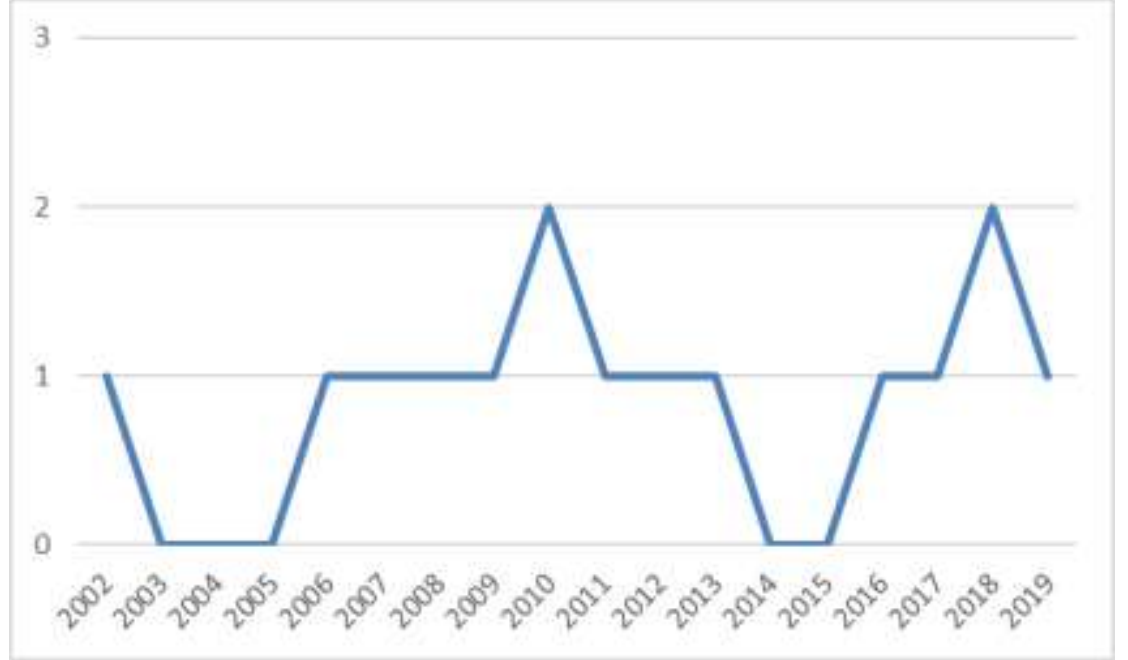

Fonte: Dados da Pesquisa (2019)

Percebe-se um hiato nos anos de 2003 a 2005 e de 2014 a 2015 com nenhum registro de produção científica relativo a esses temas. Esse resultado já indica a necessidade de pesquisas que aproximem as áreas de gestão e da mediação da informação, que conduzam à ação gestora na perspectiva da mediação, conforme defende Almeida Júnior (2015). Essa é uma ação indireta de mediação da informação.

Outra perspectiva observada, ao analisar os artigos, foi em relação aos aspectos metodológicos usados nas pesquisas publicadas. A partir de então, foi possível identificar: pesquisa de campo (3); pesquisa bibliográfica (4); estudo exploratório e descritivo abordagem quantitativa e qualitativa (3); pesquisa bibliométrica (2); pesquisa participante metodologia Cross Culture (1) e diagnóstico (1).

Optou-se por fazer uma análise transversal dividida em categorias de pesquisa. Assim, além da metodologia empregada nos artigos e dos temas em destaque - mediação e gestão da informação - foram analisados outros conteúdos temáticos com vistas a perceber as possíveis convergências entre GI e MI. Foram extraídas as menções relativas às duas áreas temáticas, que ocorreram de forma isolada e/ou conjunta nos discursos. Foram identificados os ambientes ou o lócus da pesquisa em que se desenvolvem os trabalhos.

Quanto às ligações entre a mediação da informação e a gestão da informação, apresentam os seguintes focos:

Quadro 2- Informações presentes nos artigos científicos que tratam da mediação da informação e da gestão da informação

\begin{tabular}{|c|c|c|c|c|}
\hline Autores & Métodos & Palavras-chave & $\begin{array}{c}\text { Nível de } \\
\text { interligação }\end{array}$ & Ambiente \\
\hline $\begin{array}{l}\text { SILVA, Jonathas } \\
\text { Luiz Carvalho; } \\
\text { FARIAS, Maria } \\
\text { Giovanna Guedes }\end{array}$ & $\begin{array}{l}\text { Pesquisa } \\
\text { bibliográfica }\end{array}$ & $\begin{array}{l}\text { serviços de informação; } \\
\text { competências em } \\
\text { informação; produtos de } \\
\text { informação; tecnologias } \\
\text { de informação }\end{array}$ & $\begin{array}{l}\text { Menciona a } \\
\text { gestão, mas } \\
\text { trata mais da } \\
\text { mediação da } \\
\text { informação }\end{array}$ & $\begin{array}{l}\text { Ambientes } \\
\text { de } \\
\text { informação }\end{array}$ \\
\hline $\begin{array}{l}\text { LOPES, Elaine } \\
\text { Cristina; } \\
\text { VALENTIM, }\end{array}$ & Pesquisa & disseminação & $\begin{array}{l}\text { Realiza uma } \\
\text { aproximação }\end{array}$ & $\begin{array}{l}\text { Empresas } \\
\text { de capital }\end{array}$ \\
\hline
\end{tabular}

Perspectivas em Gestão \& Conhecimento, João Pessoa, v. 10, número especial, p. 54-71, mar. 2020. 


\begin{tabular}{|c|c|c|c|c|}
\hline Autores & Métodos & Palavras-chave & $\begin{array}{c}\text { Nível de } \\
\text { interligação }\end{array}$ & Ambiente \\
\hline $\begin{array}{l}\text { Marta Lígia } \\
\text { Pomim; ALMEIDA } \\
\text { JÚNIOR, Oswaldo } \\
\text { Francisco }\end{array}$ & bibliográfica & $\begin{array}{l}\text { da informação; } \\
\text { governança corporativa }\end{array}$ & $\begin{array}{l}\text { entre a } \\
\text { mediação e a } \\
\text { gestão }\end{array}$ & aberto \\
\hline $\begin{array}{l}\text { CORDA, Maria } \\
\text { Cecília }\end{array}$ & $\begin{array}{l}\text { Estudo de } \\
\text { caso }\end{array}$ & $\begin{array}{l}\text { serviço de referência } \\
\text { digital }\end{array}$ & $\begin{array}{l}\text { Realiza uma } \\
\text { aproximação } \\
\text { entre a } \\
\text { mediação e a } \\
\text { gestão }\end{array}$ & $\begin{array}{l}\text { Biblioteca } \\
\text { Universitá } \\
\text { ria }\end{array}$ \\
\hline $\begin{array}{l}\text { SANTOS, Raquel } \\
\text { do Rosário; } \\
\text { FREITAS, Lívia } \\
\text { Santos de; } \\
\text { FERREIRA, } \\
\text { Héngret Santos; } \\
\text { MIYAMURA, } \\
\text { Camila Maria de } \\
\text { Macedo Martins }\end{array}$ & $\begin{array}{l}\text { Estudo de } \\
\text { caso }\end{array}$ & comunicação; web social & $\begin{array}{l}\text { Realiza uma } \\
\text { aproximação } \\
\text { entre a } \\
\text { mediação e a } \\
\text { gestão }\end{array}$ & $\begin{array}{l}\text { Biblioteca } \\
\text { Universitá } \\
\text { ria }\end{array}$ \\
\hline $\begin{array}{l}\text { FARIAS, Gabriella } \\
\text { Belmont de; } \\
\text { VITAL, Luciane } \\
\text { Paula }\end{array}$ & $\begin{array}{l}\text { Pesquisa } \\
\text { bibliográfica }\end{array}$ & $\begin{array}{l}\text { informação para } \\
\text { negócio; fontes de } \\
\text { Informação; política de } \\
\text { Informação }\end{array}$ & $\begin{array}{l}\text { Menciona o } \\
\text { termo } \\
\text { mediação }\end{array}$ & $\begin{array}{l}\text { Organiza- } \\
\text { ções }\end{array}$ \\
\hline $\begin{array}{l}\text { JOTTA, Carlos } \\
\text { Augusto Ribeiro }\end{array}$ & $\begin{array}{l}\text { Pesquisa } \\
\text { bibliográfica }\end{array}$ & $\begin{array}{l}\text { comutação bibliográfica; } \\
\text { planejamento } \\
\text { estratégico; } \\
\text { necessidades de } \\
\text { informação }\end{array}$ & $\begin{array}{l}\text { Realiza uma } \\
\text { aproximação } \\
\text { entre a } \\
\text { mediação e a } \\
\text { gestão }\end{array}$ & $\begin{array}{l}\text { Unidades } \\
\text { de } \\
\text { informação }\end{array}$ \\
\hline $\begin{array}{l}\text { DUARTE, Emeide } \\
\text { N. }\end{array}$ & $\begin{array}{l}\text { Pesquisa } \\
\text { documental }\end{array}$ & $\begin{array}{l}\text { redes sociais de } \\
\text { cooperação; Ciência da } \\
\text { Informação; gestão do } \\
\text { conhecimento }\end{array}$ & $\begin{array}{l}\text { Trata da } \\
\text { mediação com } \\
\text { significação, } \\
\text { mas sem } \\
\text { aproximação }\end{array}$ & $\begin{array}{l}\text { Universida } \\
\text { de }\end{array}$ \\
\hline $\begin{array}{l}\text { ARAÚJO JÚNIOR, } \\
\text { Rogério Henrique } \\
\text { de; ARAÚJO, } \\
\text { Ideliza Amélia de }\end{array}$ & Diagnóstico & $\begin{array}{l}\text { gestão da informação; } \\
\text { comutação bibliográfica; } \\
\text { planejamento } \\
\text { estratégico necessidades } \\
\text { de informação; } \\
\text { mediação da informação }\end{array}$ & $\begin{array}{l}\text { Realiza uma } \\
\text { aproximação } \\
\text { entre a } \\
\text { mediação e a } \\
\text { gestão }\end{array}$ & $\begin{array}{l}\text { Unidades } \\
\text { de } \\
\text { informação }\end{array}$ \\
\hline $\begin{array}{l}\text { FREIRE, } \\
\text { Isa Maria }\end{array}$ & $\begin{array}{l}\text { Estudo de } \\
\text { caso }\end{array}$ & $\begin{array}{l}\text { quadro teórico e } \\
\text { metodológico da } \\
\text { pesquisa Janelas da } \\
\text { Cultura Local }\end{array}$ & $\begin{array}{l}\text { Menciona o } \\
\text { termo } \\
\text { mediação ou } \\
\text { gestão uma } \\
\text { única vez }\end{array}$ & $\begin{array}{l}\text { Não se } \\
\text { aplica }\end{array}$ \\
\hline $\begin{array}{l}\text { BALBINO, Giseli } \\
\text { Milani Santiago } \\
\text { CHAGAS, Cíntia } \\
\text { Aparecida }\end{array}$ & $\begin{array}{l}\text { Pesquisa } \\
\text { bibliográfica }\end{array}$ & $\begin{array}{l}\text { arquivista; } \\
\text { multidisciplinaridade; } \\
\text { difusão; mediação; } \\
\text { orientação }\end{array}$ & $\begin{array}{l}\text { Trata da } \\
\text { mediação com } \\
\text { significação, } \\
\text { mas sem } \\
\text { aproximação } \\
\text { com a gestão }\end{array}$ & $\begin{array}{l}\text { Não se } \\
\text { aplica }\end{array}$ \\
\hline
\end{tabular}

Perspectivas em Gestão \& Conhecimento, João Pessoa, v. 10, número especial, p. 54-71, mar. 2020. 


\begin{tabular}{|c|c|c|c|c|}
\hline Autores & Métodos & Palavras-chave & $\begin{array}{c}\text { Nível de } \\
\text { interligação }\end{array}$ & Ambiente \\
\hline $\begin{array}{l}\text { DUARTE, Emeide } \\
\text { N. }\end{array}$ & $\begin{array}{l}\text { Pesquisa } \\
\text { documental }\end{array}$ & $\begin{array}{l}\text { produção científica; } \\
\text { análise de redes sociais; } \\
\text { Ciência da Informação }\end{array}$ & $\begin{array}{l}\text { Trata da } \\
\text { mediação e } \\
\text { gestão, mas } \\
\text { sem tratar } \\
\text { aprofundar os } \\
\text { temas }\end{array}$ & $\begin{array}{l}\text { Universida } \\
\text { de }\end{array}$ \\
\hline \begin{tabular}{l}
\multicolumn{2}{l}{ TARAPANOFF, } \\
Kira; SUAIDEN \\
Emir; OLIVEIRA \\
Cecília Leite
\end{tabular} & $\begin{array}{l}\text { Pesquisa } \\
\text { bibliográfica }\end{array}$ & $\begin{array}{lr}\text { profissionais } & \text { da } \\
\text { informação; funções } \\
\text { sociais; perfis de } \\
\text { profissionais } & \text { da } \\
\text { informação; Inclusão } \\
\text { digital; gestão da } \\
\text { informação; gestão do } \\
\text { conhecimento }\end{array}$ & $\begin{array}{l}\text { Trata da } \\
\text { gestão com } \\
\text { significação }\end{array}$ & $\begin{array}{l}\text { Não } \quad \text { se } \\
\text { aplica }\end{array}$ \\
\hline $\begin{array}{l}\text { CASTRO FILHO, C. } \\
\text { M. }\end{array}$ & $\begin{array}{l}\text { Análise } \\
\text { bibliométri } \\
\text { ca }\end{array}$ & $\begin{array}{l}\text { ENANCIB - grupos de } \\
\text { trabalho; trabalho de } \\
\text { conclusão de curso; } \\
\text { Ciência da Informação - } \\
\text { curso. } \\
\text {-relaciona palavras- } \\
\text { chave dos resumos dos } \\
\text { TCCs às categorias de } \\
\text { nove dos Grupos de } \\
\text { Trabalho do ENANCIB; }\end{array}$ & $\begin{array}{l}\text { Trata da } \\
\text { mediação ou } \\
\text { gestão com } \\
\text { significação, } \\
\text { mas sem } \\
\text { aproximação }\end{array}$ & $\begin{array}{l}\text { Não se } \\
\text { aplica }\end{array}$ \\
\hline $\begin{array}{l}\text { FREIRE, Isa } \\
\text { Maria; } \\
\text { NATHANSOHN, } \\
\text { B. M. }\end{array}$ & $\begin{array}{l}\text { Pesquisa- } \\
\text { participante }\end{array}$ & $\begin{array}{l}\text { inclusão digital; } \\
\text { identidade cultural; } \\
\text { gestão da informação; } \\
\text { responsabilidade social; } \\
\text { Ciência da Informação }\end{array}$ & $\begin{array}{l}\text { Trata de } \\
\text { mediação da } \\
\text { informação no } \\
\text { contexto } \\
\text { cultural, não } \\
\text { enfatiza a } \\
\text { gestão da } \\
\text { informação }\end{array}$ & Escola \\
\hline $\begin{array}{l}\text { ALENTEJO, } \\
\text { Eduardo da Silva }\end{array}$ & $\begin{array}{l}\text { Pesquisa de } \\
\text { campo em } \\
\text { três } \\
\text { bibliotecas } \\
\text { universitária } \\
\text { s da área da } \\
\text { Saúde }\end{array}$ & $\begin{array}{l}\text { avaliação de serviços em } \\
\text { bibliotecas universitárias } \\
\text { marketing de serviços } \\
\text { informação científica em } \\
\text { saúde }\end{array}$ & $\begin{array}{l}\text { Trata da } \\
\text { mediação da } \\
\text { informação } \\
\text { em saúde, não } \\
\text { enfatiza a } \\
\text { gestão da } \\
\text { informação }\end{array}$ & $\begin{array}{l}\text { Biblioteca } \\
\text { universitá- } \\
\text { ria }\end{array}$ \\
\hline $\begin{array}{l}\text { SILVA, Rafaela } \\
\text { Carolina; } \\
\text { CALDAS, } \\
\text { Rosângela } \\
\text { Formentini }\end{array}$ & $\begin{array}{l}\text { Pesquisa } \\
\text { bibliográfica }\end{array}$ & $\begin{array}{l}\text { incorporação da } \\
\text { Metodologia Cross } \\
\text { Culture ou Transcultural } \\
\text { na literatura científica da } \\
\text { área da Ciência da } \\
\text { Informação. }\end{array}$ & $\begin{array}{l}\text { Trata da } \\
\text { mediação da } \\
\text { informação no } \\
\text { contexto } \\
\text { cultural, a } \\
\text { gestão da } \\
\text { informação } \\
\text { aparece de } \\
\text { forma } \\
\text { implícita. }\end{array}$ & $\begin{array}{l}\text { Investiga a } \\
\text { análise de } \\
\text { equipamen- } \\
\text { tos culturais } \\
\text { sob o viés } \\
\text { da } \\
\text { metodolo- } \\
\text { gia Cros } \\
\text { Culture }\end{array}$ \\
\hline MIRANDA, Ana & Pesquisa & ações de mediação da & Não enfoca & Bibliotecas \\
\hline
\end{tabular}

Perspectivas em Gestão \& Conhecimento, João Pessoa, v. 10, número especial, p. 54-71, mar. 2020. 


\begin{tabular}{|c|c|c|c|c|}
\hline Autores & Métodos & Palavras-chave & $\begin{array}{c}\text { Nível de } \\
\text { interligação }\end{array}$ & Ambiente \\
\hline $\begin{array}{l}\text { Cláudia Carvalho } \\
\text { de; GALLOTTI, } \\
\text { Mônica Marques } \\
\text { Carvalho; } \\
\text { MIRANDA, Erlano } \\
\text { Silva de }\end{array}$ & bibliográfica & $\begin{array}{l}\text { informação; ações de } \\
\text { gestão da informação; } \\
\text { gestão } \\
\text { desenvolvimento } \\
\text { coleções. }\end{array}$ & $\begin{array}{l}\text { aspectos } \\
\text { diretos da } \\
\text { mediação e } \\
\text { gestão da } \\
\text { Informação. }\end{array}$ & jurídicas \\
\hline $\begin{array}{l}\text { VARELA, Aída } \\
\text { Varela; } \\
\text { BARBOSA, } \\
\text { Marilene Lobo } \\
\text { Abreu; FARIAS, } \\
\text { Maria Giovanna } \\
\text { Guedes }\end{array}$ & $\begin{array}{l}\text { Pesquisa } \\
\text { bibliográfica }\end{array}$ & $\begin{array}{l}\text { competência } \\
\text { informacional; } \\
\text { competência midiática } \\
\text { de professores e alunos }\end{array}$ & $\begin{array}{l}\text { Menciona a } \\
\text { mediação da } \\
\text { informação } \\
\text { como pré- } \\
\text { requisito para } \\
\text { a competência } \\
\text { da informação }\end{array}$ & $\begin{array}{l}\text { Universida } \\
\text { de }\end{array}$ \\
\hline $\begin{array}{l}\text { RAMOS, Lúcia } \\
\text { Verônica Costa; } \\
\text { FUJINO, Asa }\end{array}$ & $\begin{array}{l}\text { Pesquisa } \\
\text { documental } \\
\text { e estudo de } \\
\text { caso }\end{array}$ & $\begin{array}{l}\text { divulgação da Ciência e } \\
\text { Tecnologia (C\&T); } \\
\text { mediação da informação } \\
\text { no atendimento a } \\
\text { usuários }\end{array}$ & $\begin{array}{l}\text { Trata da } \\
\text { mediação da } \\
\text { informação e } \\
\text { não trata de } \\
\text { gestão }\end{array}$ & $\begin{array}{l}\text { Redes de } \\
\text { Informação } \\
\text { Científica na } \\
\text { área } \\
\text { odontológi- } \\
\text { ca }\end{array}$ \\
\hline
\end{tabular}

Fonte: Dados da pesquisa (2019)

A partir da análise do Quadro 2, é possível observar que ainda é insipiente o número de artigos que apresentam a inter-relação entre a mediação e a gestão da informação. Por outro lado, esses temas são discutidos de maneira desassociada, focalizando em um ou outro. Assim, com base na amostra analisada, pode-se afirmar que os temas tratados - mediação da informação e gestão da informação - ainda não têm sido abordados de maneira verticalizada com base nas suas possíveis convergências.

Para visualizar bem mais essas constatações, elencaram-se, a seguir, os níveis de interligação percebidos nos artigos.

a) menciona apenas o termo mediação ou gestão: Farias e Vital (2007); Freire (2006); Freire e Espírito-Santo (2009) e Ramos (2013);

b) menciona a gestão no geral sem relacionar com informação ou mediação: Alentejo (2010); Silva e Caldas (2019);

c) trata da mediação ou gestão como operador lógico: Silva e Farias (2017); Duarte (2011); Barbosa e Farias (2017);

d) trata da mediação ou gestão com significação, mas sem aproximação: Duarte (2012); Balbino e Chagas (2018); Tarapanoff, Suaiden e Oliveira (2002); Castro Filho (2010); Miranda e Gallotti (2016);

e) realiza uma aproximação entre a mediação e a gestão: Lopes, Valentin e Almeida Júnior (2011); Corda (2012); Santos e outro autores (2018); Jotta (2015); Araújo Júnior e Araújo (2008).

Vela ressaltar que, em alguns casos apresentados no Quadro 2, só foram citadas as palavras gestão e/ou mediação da informação, mas sem tratar do seu significado no campo da Ciência da Informação. E como a gestão da informação, conforme defende Valentim (2004), é um conjunto de atividades estratégicas que visam identificar as necessidades informacionais para a tomada de decisão, o gestor da informação, ao desenvolver essas atividades na perspectiva da mediação da informação, deverá atuar, conforme indica Gomes $(2014,2016)$, de modo a alcançar a dialogia, propiciando os espaços de interação que possibilitam aos sujeitos vivenciarem o prazer de realizar as ações, alcançando a dimensão estética e 
oportunizando o processo de aprendizagem e de formação, quando nas ações gestoras, por meio do aporte da mediação, visando alcançar sua dimensão formativa. Assim, ainda conforme Gomes (2016), na perspectiva da mediação da informação, os gestores da informação só poderão auxiliar a tomada de decisão, apoiar a apropriação da informação e, consequentemente, gerar novos saberes e conhecimentos, se realizarem essa interferência conscientes de sua condição de protagonistas sociais, para evitar a manipulação, portanto, a partir do alcance da dimensão ética e política da mediação da informação.

Tanto a mediação da informação quanto a gestão da informação estão interrelacionadas com outras ações, portanto, os pesquisadores realizarão essa convergência em suas comunicações, conforme demonstrado a seguir:

a) Serviços de Informação (SILVA, FARIAS, 2017); Serviço de Referência Digital (CORDA, 2012); Comutação Bibliográfica (ARAÚJO JÚNIOR, R. H.; ARAÚJO, I. A, 2019); (JOTTA, C. A. R., 2019) e Avaliação de serviços (ALENTEJO, 2010);

b) Profissional da Informação (TARAPANOFF, 2002);

c) Competência em Informação (SILVA; FARIAS, 2017) e (VARELA; BARBOSA; FARIAS, 2017) - o termo mediação aparece como operador lógico;

d) Informação para Negócios (FARIAS; VITAL, 2007);

e) Planejamento Estratégico (ARAÚJO JÚNIOR; ARAÚJO,2008);

f) Multidisciplinaridade (BALBINO: CHAGAS, 2018);

g) Inclusão Digital e Responsabilidade Social (FREIRE, et al, 2009): (FREIRE, 2006);

h) Comunicação e Web social (SANTOS; FREITAS, FERREIRA; MIYAMURA, 2018).

Percebe-se que, ao tratar da mediação e da gestão da informação, outros temas relacionados às práticas informacionais dos profissionais da informação são identificados. Os termos aparecem atrelados a organizações - sejam unidades de informação ou outros tipos de organizações. É possível identificar que existe uma incorporação do termo mediação da informação em artigos que tratam dos serviços de informação em unidades de informação. Isso se faz presente em discursos relativos a ações como as realizadas em serviços de referência convencionais e virtuais bem como em ações voltadas para o desenvolvimento das coleções.

Para além dessa convergência, foi possível verificar que o termo gestão da informação está atrelado a trabalhos relacionados à informação para negócios e planejamento estratégico. Além disso, o termo mediação da informação está presente em textos que tratam sobre a responsabilidade social e a inclusão digital bem como o que trata de comunicação e web social, na qual se pode inferir que, no campo da comunicação e da inclusão digital, as ações de mediação da informação são necessárias. Vale destacar a necessidade dos pesquisadores e dos profissionais refletirem sobre as inter-relações entre a mediação e a gestão da informação sem limitar o planejamento estratégico à discussão do tema gestão, mas percebendo que toda a ação, direta ou indireta realizada pelo profissional da informação, deve ser subsidiada pela perspectiva mediadora e o agir estratégico e sistemático, portanto, consciente.

Diante do exposto, pode-se inferir: 1) que a convergência dessas duas áreas científicas ainda está sendo construída e debatida na comunidade científica; 2) que poucos artigos indicam a interligação possível entre as duas áreas; 3 ) que os autores percebem que a mediação da informação é inerente aos serviços de informação em contextos variados; 4) há uma compreensão de que a mediação da informação é uma ação-base para processos de gestão da informação em organizações; 5) a mediação da informação, por vezes, é mencionada como um operador lógico, e não, tratada como categoria científica no corpus arrolado; 6) embora presentes, as relações entre as duas categorias, em algumas circunstâncias, não são explicitadas. No entanto, por meio da análise, é possível perceber que esses dois temas aparecem, algumas vezes, dissociadas nos trabalhos arrolados.

Perspectivas em Gestão \& Conhecimento, João Pessoa, v. 10, número especial, p. 54-71, mar. 2020. 


\section{CONSIDERAÇÕES FINAIS}

Este trabalho partiu da necessidade de se buscarem discursos complementares de duas áreas científicas importantes: a gestão da informação e a mediação da informação. Os resultados indicaram que, a partir das reflexões teóricas desenvolvidas nesta comunicação, foi possível entender a inter-relação entre a mediação e a gestão da informação: esta última, percebida a partir do conceito de Almeida Júnior (2015), como uma ação implícita. Entretanto, a gestão também é um processo que norteia todas as demais ações implícitas e explícitas de mediação da informação e não se encerra em si mesma ou em uma etapa, mas proporciona o posicionamento dos demais agentes como mediadores, subsidiando suas ações na busca pelo alcance das dimensões dialógica, estética, formativa, ética e política da mediação proposta por Gomes $(2014,2016)$.

Por outro lado, a pesquisa deixou claro que a maioria dos pesquisadores trata a mediação e a gestão como elementos que mantêm algum nível de aproximação, mas, em seus estudos, focalizam uma ou outra temática sem fazer uma ligação entre elas. As comunicações focalizaram na gestão da informação ou na mediação da informação, sendo que, em alguns casos, a mediação ou a gestão da informação são apresentadas de maneira subliminar. Assim, defende-se a relevância do desenvolvimento de estudos que conduzam a gestão pelos fundamentos propostos da mediação da informação, o que poderá ampliar a perspectiva que o gestor terá do seu fazer. Nesse contexto, um mediador da informação é que apoiará a adoção de uma cultura organizacional em que os demais profissionais atuem também como mediadores, favorecendo uma relação dialógica com os usuários que apoiará o uso e a apropriação da informação.

Os resultados indicaram, também, que existe uma variedade de termos interligados tanto quando se focaliza a gestão quanto a mediação da informação. Essa contratação reafirma o lugar da gestão como um processo que não se limita a uma única etapa no desenvolvimento organizacional, mas subsidiará todas as ações implícitas e explicitas de mediação da informação. Por outro lado, a mediação da informação é uma concepção do fazer dos profissionais que só será adotada se o gestor entender e levar a equipe a atuar na perspectiva de mediadores da informação.

\section{REFERÊNCIAS}

ALENTEJO, E. S. Qualidade da informação em saúde mediada em biblioteca pela percepção de seus usuários. Biblionline, v. 6, n. 1, 2010. Disponível em: https://bit.ly/36Qp5VR. Acesso em: 18 set. 2019.

ALMEIDA JÚNIOR, Oswaldo Francisco de. Mediação da informação: um conceito atualizado. In: Mediação oral da informação e da leitura. Londrina: ABECIN, 2015. p. 9-32.

ALVES, M. S.; CORREIA, A. E. G. C.; SALCEDO, D. A. Práticas leitoras e informacionais nas bibliotecas comunitárias em rede da releitura - PE. Revista Digital de Biblioteconomia \& Ciência da Informação, v. 16, n. 1, 2018. Disponível em: https://bit.ly/33xycZy. Acesso em: 18 set. 2019.

ARAÚJO JÚNIOR, R. H.; ARAÚJO, I. A. Modelo de gestão da informação do programa de comutação bibliográfica - comut. Informação \& Sociedade: Estudos, v. 18, n. 1, 2008. Disponível em: https://bit.ly/36TPody. Acesso em: 18 set. 2019.

Perspectivas em Gestão \& Conhecimento, João Pessoa, v. 10, número especial, p. 54-71, mar. 2020. 
BALBINO, G. M. S.; CHAGAS, C. A. Papel pedagógico do arquivista e sua inserção na difusão e mediação da informação. Ágora, v. 28, n. 57, 2018. Disponível em: https://bit.ly/2Q6aOyq. Acesso em: 18 set. 2019.

BARDIN. L. Análise de conteúdo. Lisboa: Editora Edições 70, 1977.

BORTOLIN, Sueli; SANTOS NETO, João Arlindo dos; SILVA, Rovilson José da (org.). Mediação oral da informação e da leitura. Londrina: ABECIN, 2015. p. 9-32.

CASTRO FILHO, C. M. A pesquisa de graduação: o caso dos TCCS da USP - Ribeirão em relação aos GTS do ENANCIB. InCID: Revista de Ciência da Informação e Documentação, v. 1 n. 2, n. 2, 2010. Disponível em: https://bit.ly/2NWnV2w. Acesso em: 18 set. 2019.

CHOO, Chun Wei. A organização do conhecimento: como as organizações usam a informação para criar significado, construir conhecimento e tomar decisões. Trad. Eliana Rocha. 2.ed. São Paulo: Editora Senac, 2006. 421p.

CORDA, M. C. Gestão e mediação da informação em um serviço de referência digital no campo das ciências sociais. Brazilian Journal of Information Science, v. 6, n. 2, 2012. Disponível em: https://bit.ly/2Cy2D5L. Acesso em: 18 set. 2019.

DUARTE, E. N. Conteúdos temáticos como subsídios para indicação de colaboração na Ciência da Informação: PPGCI/UNESP e PPGCI/UFPB em evidência. Informação \& Sociedade: Estudos, v. 22, 2012. Disponível em: https://bit.ly/2p4tqDI. Acesso em: 18 set. 2019.

DUARTE, E.N. Conexões temáticas em gestão da informação e do conhecimento no campo da Ciência da Informação: proposta de redes humanas. Informação \& Sociedade: Estudos, João Pessoa, v.21, n.1, p. 159-173, jan./abr. 2011. Disponível em: https://bit.ly/2022rkA. Acesso em: 14 set. 2019.

FARIAS, G. B.; VITAL, L. P. Informação para negócios e políticas de informação. Revista ACB: Biblioteconomia em Santa Catarina, v. 12, n. 1, 2007. Disponível em: https://bit.ly/32vgOmV. Acesso em: 18 set. 2019.

FREIRE, I. M. Acesso à informação e identidade cultural: entre o global e o local. Ciência da Informação, v. 35, n. 2, 2006. Disponível em: https://bit.ly/2Q6tT3i. Acesso em: 18 set. 2019.

FREIRE, I. M.; NATHANHSON, B. M. Janelas da cultura local: abrindo oportunidades para inclusão digital. Revista Digital de Biblioteconomia \& Ciência da Informação, v. 7, n. 1, 2009. Disponível em: https://bit.ly/2NAgNK4.. Acesso em: 18 set. 2019.

GOMES, Henriette Ferreira. A dimensão dialógica, estética, formativa e ética da mediação da informação. Inf. Inf., Londrina, v. 19, n. 2, p. 138 - 170, maio/ago. 2014. Disponível em: https://bit.ly/2NxLCz6. Acesso em: 14 set. 2019.

GOMES, Henriette Ferreira. Comunicação e informação: relações dúbias, complexas e intrínsecas. In: MORIGI, Valdir; JACKS, Nilda; GOLIN, Cida (Orgs.). Epistemologias, comunicação e informação. Porto Alegre: Sulina, 2016. p. 91-107.

Perspectivas em Gestão \& Conhecimento, João Pessoa, v. 10, número especial, p. 54-71, mar. 2020. 
GOMES, Henriette Ferreira. Mediação da informação e protagonismo social: relações com vida ativa e ação comunicativa à luz de Hannah Arendt e Jurgen Habermas. In: GOMES, Henriette Ferreira; NOVO, Hildenise Ferreira (Orgs.). Informação e protagonismo social. Salvador: EDUFBA, 2017, p. 27-43.

JOTTA, C. A. R. Mediação científica em museus de ciência e tecnologia: abordagem acerca da coleção de instrumentos científicos de Claude Henri Gorceix. Revista Analisando em Ciência da Informação, v. 3, n. 2, 2015. Disponível em: https://bit.ly/32A0ocE. Acesso em: 18 set. 2019.

LOPES, E. C.; VALENTIM, M. L. P.; ALMEIDA JÚNIOR, O. F. Disseminação da informação em empresas de capital aberto e os processos de mediação da informação. Em Questão, v. 17, n. 1, 2011. Disponível em: https://bit.ly/2Cs9k9H. Acesso em: 18 set. 2019.

MIRANDA, A. C. C.; GALLOTTI, M. M. C.; MIRANDA, E. S. A gestão da qualidade como estratégia de suporte para o desenvolvimento de coleções em bibliotecas jurídicas. Revista Digital de Biblioteconomia \& Ciência da Informação, v. 14, n. 2, 2016. Disponível em: https://bit.ly/34PnnSN. Acesso em 12 out 2019.

PERROTTI, Edmir; PIERUCCINI, Ivete. A mediação cultural como categoria autônoma. Informação \& Informação, v. 19, n. 2, p. 01-22, out. 2014. Disponível em: https://bit.ly/2rtFC1D. Acesso em: 11 out. 2019.

PIERUCCINI, Ivete. Ordem informacional dialógica: mediação como apropriação da informação. In: ENCONTRO NACIONAL DE PESQUISA EM CIÊNCIA DA INFORMAÇÃO, 8., 2007, Salvador. Anais [...]. Salvador: Universidade Federal da Bahia, 2007. 1 CD-ROM.

PINHEIRO, Marta Macedo Kerr. Mediações híbridas para uma gestão da informação compartilhada. Inf., Londrina, v. 13, n. esp, p.39-51, 2008. Disponível em: https://bit.ly/33zROXP. Acesso 12 out 2019.

PINTO, Maria Manuela Gomes de Azevedo. Gestão da informação: para um mapeamento de abordagens e perspectivas. Páginas a\&b, S.3, no especial (2017) p.144-157 | DOI 10.21747/21836671/pag2017a10.

RAMOS, L. V. C.; FUJINO, A. Redes de informação científica e os desafios para popularização da ciência: estudo de caso na Rede SIEO - sistema de informação especializado na área de Odontologia. Informação \& Informação, v. 18, n. 1, 2013. Disponível em: https://bit.ly/2NZsGII. Acesso em: 18 set. 2019.

SANTOS, R. R.; FREITAS, L. S.; FERREIRA, H. S.; MIYAMURA, C. M. M. M. Expectativas dos usuários quanto ao desenvolvimento do dispositivo de comunicação da biblioteca universitária. Encontros Bibli: Revista Eletrônica de Biblioteconomia e Ciência da Informação, v. 23, n. 51, 2018. Disponível em: https://bit.ly/2XOKs29. Acesso em: 18 set. 2019.

SILVA, Armando Malheiro da. A informação: da compreensão do fenómeno e construção do objecto científico. Porto: Afrontamento, 2006. 176p.

Perspectivas em Gestão \& Conhecimento, João Pessoa, v. 10, número especial, p. 54-71, mar. 2020. 
SILVA, J. L. C.; FARIAS, M. G. G. Abordagens conceituais e aplicativas da mediação nos serviços de informação. InCID: Revista de Ciência da Informação e Documentação, v. 8 n. 2, 2017. Disponível em: https://bit.ly/2Xb4gQF. Acesso em: 18 set. 2019.

SILVA, Jonathas Luiz Carvalho; GOMES, Henriette Ferreira. A importância da mediação para a construção de uma autonomia no contexto dos usuários da informação. Informação \& Sociedade: estudos, João Pessoa, v.23, n.2, p. 33-44, maio/ago. 2013. Disponível em: https://bit.ly/2K8IK9M. Acesso em: 11 out. 2019.

SILVA, R. C.; CALDAS, R. F. O método cross culture na pesquisa em Ciência da Informação. Revista Ibero-Americana de Ciência da Informação, v. 12, n. 3, 2019. Disponível em: https://bit.ly/2K4KzV6. Acesso em: 18 set. 2019.

TARAPANOFF, K.; SUAIDEN, E. J.; OLIVEIRA, C. L. Funções sociais e oportunidades para profissionais da informação. DataGramaZero, v. 3, n. 5, 2002. Disponível em: https://bit.ly/2NyTtfF. Acesso em: 18 set. 2019.

VALENTIM, Marta Lígia Pomim. Gestão da informação e gestão do conhecimento: especificidades e convergências. Ofaj, [S.I.], 2004.Disponível em: https://bit.ly/36TQy8U. Acesso em: 14 set. 2019.

VALENTIM, Marta Lígia Pomim. O moderno profissional da informação: formação e perspectiva profissional. Enc. Bibli: R. Eletr. Bibliotecon. Ci. Inf., ISSN 1518-2924, Florianópolis, Brasil, n.9, p.16-28, 2000. Disponível em: https://bit.ly/2X0KV4p. Acesso em: 14 set. 2019.

VARELA, A. V.; BARBOSA, M. L. A.; FARIAS, M. G. G. Humanismo e tecnologia na perspectiva da competência informacional e midiática. Revista Brasileira de Biblioteconomia e Documentação, v. 13, n. Especial, 2017. Disponível em: https://bit.ly/201JDIF. Acesso em: 18 set. 2019.

VYGOTSKY, L. A formação social da mente: o desenvolvimento dos processos psicológicos superiores. 6. ed. São Paulo: Martins Fontes, 2000.

Artigo recebido em 30/11/2019 e aceito para publicação em 27/02/2020

Perspectivas em Gestão \& Conhecimento, João Pessoa, v. 10, número especial, p. 54-71, mar. 2020. 